\title{
The Rare Intracellular RET mutation p.S891A in a Turkish Family With Hereditary Medullary Thyroid Carcinoma
}

\author{
Caglar Keskin, Sevim Gullu
}

Ankara University, Faculty of Medicine, Department of Endocrinology and Metabolic Diseases, Ankara

\author{
Objectives: \\ Medullary thyroid carcinoma (MTC) could be familial in $30 \%$ of cases. Here we report a family of FMTC with \\ rarely seen RET p.S891A mutation.
}

A 49-year-old man presented with a single nodule in the left lobe of thyroid. Thyroid ultrasonography (US) showed a nodule and pathological cervical lymph nodes. There was no relevant family history. Fine-needle aspiration cytology (FNAC) of the nodule was consistent with a diagnosis of medullary thyroid carcinoma. Serum calcitonin level was $906 \mathrm{pg} / \mathrm{mL}$ (reference range 0 to $18 \mathrm{pg} / \mathrm{mL}$ ) and the other laboratory tests, parathormone level and 24-h urine catecholamine levels were normal. An extensive RET molecular analysis identified the rare intracellular RET p.S891A mutation. Then the patient underwent total thyroidectomy and bilateral neck dissection. Histopathology revealed medullary thyroid carcinoma pT1bN1bM0 with capsular and lymphovascular invasion and lymph node metastases. Serum calcitonin and carcinoembryonic antigen levels measured three months after the surgery was $569 \mathrm{pg} / \mathrm{mL}$ and $12 \mathrm{ng} / \mathrm{mL}$ respectively. During the follow up there was progressive rise in calcitonin and CEA levels. No distant metastases were detected. Since there were cervical pathological lymph nodes he was planned to have revision operation. RET p.S891A mutation was also detected at his daughter. She was completely asymptomatic and baseline serum calcitonin level was normal. Calcium stimulation test showed no marked increase in CT levels therefore prophylactic thyroidectomy was postponed.

\section{Conclusions:}

We reported a patient who presented all characteristic features of sporadic MTC but extensive molecular analysis revealed rarely seen intracellular RET p.S891A mutation and his daughter had same mutation. RET genetic screening is very important tool for the preclinical diagnosis and early treatment of unsuspected affected family members.

\section{References:}

1. Machens, A., et al., Early malignant progression of hereditary medullary thyroid cancer. N Engl J Med, 2003. 349(16): p. 1517-25.

2. Blom, C.B., et al., The rare intracellular RET mutation p.Ser891Ala in an apparently sporadic medullary thyroid carcinoma: a case report and review of the literature. Arq Bras Endocrinol Metabol, 2012. 56(8): p. 586-91.

3. Berndt, I., et al., A new hot spot for mutations in the ret protooncogene causing familial medullary thyroid carcinoma and multiple endocrine neoplasia type 2A. J Clin Endocrinol Metab, 1998. 83(3): p. 770-4. 